\title{
Indonesian YouTube Videos as a Source of Tooth Whitening Information
}

\author{
Laura Vita Catherine Naibaho ${ }^{1}$ Naufal Rifqi Aulia', Yuanita Lely Rachmawati ${ }^{2}$ \\ ${ }^{1}$ Undergraduate school, Faculty of Dentistry, Universitas Brawijaya, Indonesia \\ ${ }^{2}$ Department of Community and Preventive Dentistry, Faculty of Dentistry, Universitas Brawijaya, Indonesia
}

Objectives: Currently, YouTube is still a favorite channel to get information for free. This study aimed to analyze the quality of Indonesian videos on YouTube uploaded by health professionals and non-health professionals about tooth whitening.

Methods: The two keywords used in the search were tooth whitening (memutihkan gigi) and dental bleaching (bleaching gigi). From each keyword, 100 videos that appear first in YouTube and meet the inclusion criteria were taken. The inclusion criteria were videos according to keywords and in Indonesian. The exclusion criteria were duplicate videos, videos without likes and dislikes, conference or lecture videos that require a particular audience. Videos were analyzed by counting likes/dislikes, viewers, popularity, visibility, and DISCERN score. Two observers selected Videos independently, and their reliability was measured using Intraclass Correlation Coefficient (ICC) with a reference value $>0.8$. Data analysis used the Mann-Whitney test to see the difference between health professionals and non-health professionals.

Results: A total of 106 YouTube videos were selected according to the inclusion criteria from 200 downloaded videos. Most of the uploaders were non-health professionals (70.8\%). There were significant differences in dislike, number of viewers, popularity, and DISCERN scores between health professionals and non-health professionals $(\mathrm{p}<0.05)$. Non-professional uploaders had higher dislike and visibility. For popularity, it is higher in health professionals. For DISCERN score, health professionals provide more accurate information.

Conclusions: Information about tooth whitening or dental bleaching should be from a health professional to avoid inaccurate information. YouTube viewers to be more selective when choosing videos as a source of tooth whitening information.

Keywords: tooth whitening, dental bleaching, video analysis, YouTube

Copyright (C) 2021. Korean Academy of Preventive Dentistry. All rights reserved.

This is an Open Access article distributed under the terms of the Creative Commons Attribution Non-Commercial License (http://creativecommons.org/licenses/ by-nc/4.0) which permits unrestricted non-commercial use, distribution, and reproduction in any medium, provided the original work is properly cited. 